UDC 342,316

Submitted: 06.09.2019

LBC 60.56

Accepted: 01.10.2019

\title{
LEGAL AWARENESS DYNAMICS OF THE POPULATION OF THE SOUTH OF RUSSIA: COGNITIVE ASPECT ${ }^{1}$
}

\author{
Lyudmila V. Klimenko \\ Southern Federal University, Rostov-on-Don, Russian Federation \\ Oksana Yu. Posukhova \\ Southern Federal University, Rostov-on-Don, Russian Federation \\ Pavel E. Budaev \\ Southern Federal University, Rostov-on-Don, Russian Federation
}

\begin{abstract}
Introduction: the integration processes in the South of Russia are complicated by the ethno-cultural heterogeneity of the macroregion, different levels of socio-economic development of the subregions and differences in the societal values of the ethno-territorial communities. In these conditions, a similar legal culture serves as the basis for the consolidation of different groups of the population. The purpose of the paper is to analyze the dynamics of the legal culture cognitive component of the population of the multi-ethnic territories of Southern Russia. Methods: the empirical basis of the study was formed as part of comparative sociological research, when more than two thousand people were interviewed in the Rostov region, Adygea and KabardinoBalkaria in 2001-2019. Results: as a rule, the legal culture of a civil-activist type should dominate in a modernized society, when the population understands and recognizes the priority of human rights and freedoms, legal responsibility, shows respect for the existing laws. Therefore, the study of the cognitive components of the legal culture of South-Russian residents includes the analysis of knowledge and perceptions of the respondents about the basic signs of the legal state, the permissibility of limitations of human rights, the degree of importance of the rights of different actors in society, the status of law, legislation in the case of administrative arrest and witness testimony. Conclusions: the empirical tests show a rather low level of specific legal knowledge of the population in all the considered territorial subjects of the South of Russia. Moreover, from the first to the last stages of the study, the dynamics of the knowledge level is decreasing. The priority of the right is not always manifested in the attitudes of the surveyed residents in the macroregion. Against this background, in the Rostov region at different stages of the study a stable group of respondents (about half of the respondents), for whom 2 the legal norm is a legitimate regulator of behavior, was recorded. In the republican segment, the situation is $\vec{\sim}$ volatile; the lagging dynamics of legal systems of a civil type in the Republic of Adygea and the accelerating if one - in Kabardino-Balkaria are revealed.

Key words: legal culture, polyethnic region, the South of Russia, legal knowledge, the North Caucasus \& republics, ethno-cultural specificity, societal integrity.

Citation. Klimenko L.V., Posukhova O.Yu., Budaev P.E. Legal Awareness Dynamics of the Population of the South of Russia: Cognitive Aspect. Legal Concept, 2019, vol. 18, no. 4, pp. 75-82. (in Russian). DOI: https://doi.org/10.15688/lc.jvolsu.2019.4.10

\section{ДИНАМИКА ПРАВОВОГО СОЗНАНИЯ НАСЕЛЕНИЯ ЮГА РОССИИ: КОГНИТИВНЫЙ АСПЕКТ ${ }^{1}$}

\author{
Людмила Владиславовна Клименко \\ Южный федеральный университет, г. Ростов-на-Дону, Российская Федерация
}




\section{ТЕОРИЯ И ПРАКТИКА ГОСУДАРСТВЕННО-ПРАВОВОГО РАЗВИТИЯ}

\section{Оксана Юрьевна Посухова}

Южный федеральный университет, г. Ростов-на-Дону, Российская Федерация

Павел Евгеньевич Будаев

Южный федеральный университет, г. Ростов-на-Дону, Российская Федерация

Введение: интеграционные процессы на Юге России затруднены этнокультурной гетерогенностью макрорегиона, разным уровнем социально-экономического развития субрегионов и различиями социетальных ценностей этнотерриториальных сообществ. В этих условиях однородная правовая культура выступает основанием консолидации различных групп населения. Цель статьи - анализ динамики когнитивного компонента правовой культуры населения полиэтничных территорий Юга России. Методы: эмпирическая база сформирована на основе повторно-сравнительных социологических исследований, полученных в 20012019 гг. при опросе более 2000 человек в Ростовской области, республиках Адыгее и Кабардино-Балкарии. Результаты: в модернизированном обществе должна, как правило, доминировать правовая культура гражданско-активистского типа, когда население понимает и признает приоритет прав и свобод человека, правовую ответственность, проявляет уважение к действующим законам. Поэтому изучение когнитивного компонента правовой культуры жителей Юга России включает анализ знаний и представлений респондентов о базовых признаках правового государства, допустимости ограничения прав человека, степени важности прав различных субъектов общества, статусе закона, законодательных нормах в случае административного задержания и дачи свидетельских показаний. Выводы: эмпирические замеры показывают достаточно низкий уровень конкретных правовых знаний населения во всех рассматриваемых территориальных суббъектах Юга России. Причем от первого к последнему этапам исследования динамика уровня знаний понижающаяся. Приоритет права далеко не всегда проявляется в установках опрошенных жителей макрорегиона. На этом фоне, в Ростовской области на разных этапах исследования фиксируется устойчивая группа респондентов (около половины опрошенных), для которых правовая норма - легитимный регулятор поведения. В республиканском сегменте ситуация подвижная, выявляется запаздывающая динамика правовых установок гражданского типа в Адыгее и ускоряющаяся в Кабардино-Балкарии.

Ключевые слова: правовая культура, полиэтничный регион, Юг России, правовые знания, республики Северного Кавказа, этнокультурная специфика, социетальная целостность.

Цитирование. Клименко Л. В., Посухова О. Ю., Будаев П. Е. Динамика правового сознания населения Юга России: когнитивный аспект // Legal Concept = Правовая парадигма. -2019 . - T. 18, № 4. - C. 75-82. - DOI: https://doi.org/10.15688/lc.jvolsu.2019.4.10

\section{Введение}

Любое многосоставное общество испытывает потребность в интеграции и сохранении социальной устойчивости. В обеспечении и поддержании социальной интеграции одну из центральных ролей играет правовая система. Правовые институты являются инструментами интеграции социальных общностей на основе единых правокультурных норм, ценностей и моделей поведения. Модернизационный вектор развития нашей страны, включающий в качестве важнейшего направления задачу формирования правового государства, предполагает складывание в обществе однородной правовой культуры гражданского типа. Однако этот процесс сопряжен с рядом трудностей, выраженных в разных представлениях населения о законе и справедливости, способах организации вла- сти, принципе регулирования социальных взаимодействий и характере наказаний.

Наиболее сложной данная проблема является для полиэтничных регионов с укоренившимися компонентами национальных культур. Особым разнообразием этнокультурного состава населения отличается Юг России. Данный макрорегион, включающий Южный и Северо-Кавказский федеральные округа, продолжает оставаться субъектом, дробящимся на сегменты, границы которых носят не только административный, но и религиозный, языковой, этнический характер $[1 ; 4 ; 10]$. Одной из специфических черт Юга России является сложное переплетение двух соционормативных систем - этнокультурной традиции и права, претендующих на доминирующую роль в организации жизни социума. Народы Северного Кавказа, несмотря на модернизационные процессы, во многом сохранили свои тради- 
ционные институты как важный фактор социального воспроизводства.

Вместе с тем соответствие правовых ценностей и установок различных групп населения поликультурных регионов - это важнейший залог солидарного взаимодействия как основания и характерного содержания социетального (макроуровневого) единства общества [6]. Подобная постановка проблемы является целью исследования этнокультурной специфики правовой культуры населения Юга России в контексте социетальной динамики макрорегиона. В рамках настоящей статьи рассмотрим динамику когнитивного компонента правовой культуры жителей полиэтничных территорий Юга России (на материалах эмпирических исследований 2001-2019 гг.).

\section{Методы исследования}

Ученые указывают, что «право является основным, определяющим атрибутом нашего общественного сознания» [ 11 , c. 359], поэтому необходимо осмысление восприятия населением сложившейся конфигурации нормативно-правовой и социокультурных систем. Наиболее распространенным подходом к анализу правовой культуры населения является изучение составляющих ее структурных элементов - правовых знаний, ценностей и моделей поведения [3]. В интеграционных процессах правосознание (знания и ценности) играет ключевую роль, то есть легитимизирует и интернализирует правокультурные установления. Это в свою очередь выступает основанием консолидации различных групп населения.

В модернизированном обществе должна, как правило, доминировать правовая культура гражданско-активистского типа, когда население понимает и признает приоритет прав и свобод человека, правовую ответственность, проявляет уважение к действующим законам $[2 ; 5 ; 8]$. Работы зарубежных ученых показывают, что внедрение современных норм права на территориях традиционной культуры влечет повышение уровня справедливости в целом [12].

Для анализа динамики правовой культуры поликультурных регионов проводилась серия повторно-сравнительных социологических исследований в нескольких административнотерриториальных образованиях Юга России:

- в Республике Адыгея (в 2001 г. опрошено 188 адыгейцев, в 2011 г. - 210, в 2019 г. - 328);

- в Кабардино-Балкарской Республике (в 2001 г. опрошено 208 балкарцев, в 2019 г. 347 кабардинцев и балкарцев);

- Ростовской области (в 2010 г. опрошено 374 человек, в 2019 г. - 396).

Метод опроса - стандартизированное интервью. Отбор респондентов по поло-возрастным и территориальным квотам происходил по месту проживания (столицы республик и административные центры областей).

\section{Результаты исследования}

Анализ когнитивного компонента правовой культуры предполагает изучение показателей знания и понимания населением правовых норм функционирования современного общества, законодательных регуляторов поведения граждан.

Важным знаниевым маркером гражданско-активистского типа правовой культуры является знание населением базовых признаков правового государства. Результаты исследования показывают низкую степень информированности жителей Юга России в данном вопросе. В наибольшей степени осведомлено население Ростовской области, причем за последние 10 лет растет количество «правильных» ответов (защита гражданских прав, приоритет закона, разделение ветвей власти). В республиках Северного Кавказа за исследуемый период, наоборот, сокращается совокупное число ответов, характеризующих атрибуты правового государства. Наиболее заметна отрицательная динамика по позициям обеспечения защиты прав и свобод граждан, а также разделению исполнительной, законодательной и судебной власти. Однако необходимо отметить, что среди городского населения Адыгеи и Кабардино-Балкарии возрос процент установок на доминирование права и закона по отношению к морали или традициям (см. табл. 1).

Анализ результатов ответа на вопрос о том, в каких случаях допустимо ограничение прав человека, показал, что на современ- 


\section{ТЕОРИЯ И ПРАКТИКА ГОСУДАРСТВЕННО-ПРАВОВОГО РАЗВИТИЯ}

ном этапе не больше трети опрошенных жителей Юга России признает абсолютную значимость гражданских прав, а именно: в 2019 г. отметили, что права человека нельзя ограничивать ни при каких условиях, 20,5 \% респондентов в Ростовской области, 19,8 \%в Адыгее, 34,9 \% - в Кабардино-Балкарии. От первого к последнему этапам опроса распространенность подобных представлений сокращается в ростовском и адыгейском сегментах. На первое место по числу ответов выходит позиция, согласно которой права человека допустимо ограничивать «если это нужно для поддержания порядка и стабильности» $(35,9 \%$ - в РО, 20,4 \% - в РА, $25,9 \%$ - в КБР). Однако за рассматриваемый период в северокавказских республиках количество респондентов, разделяющих эту ориентацию, уменьшается (в РА - с $38,8 \%$ в 2011 г. до 20,4 \% в 2019 г., в КБР - с 38,9 до $25,9 \%$ соответственно).

Таким образом, среди правовых приоритетов права личности далеко не всегда выходят на первое место в сознании населения Юга России. Подобный запрос на стабильность и сильное государство, характерный для российского населения в целом, фиксируют многие специалисты. Одной из причин этого называют реакцию на постоянные политические и экономические преобразования, состояние длительной социальной транзиции. Поэтому устойчивой является «спайка в сознании многих россиян идей свободы и безопасности в надежде на такой социальный порядок, который бы обеспечивал и то, и другое» [7, с. 26].

Исследование когнитивного измерения правовой культуры предполагает также анализ существующего уровня знаний законодательных установлений, необходимых для принятия гражданами решений в возможных жизненных ситуациях.

Административное задержание является одной из наиболее часто используемых на практике мер административно-процессуального обеспечения [9, с. 195]. Статья 27.5 КоАП РФ определяет общий (3 ч) и специальный (48 ч) сроки административного задержания. Результаты опросов показывают, что на разных этапах осведомленность населения в этом вопросе достаточно низкая. Не больше трети опрошенных смогли верно указать возможные сроки административного задержания. Причем от первого к последнему этапам исследования динамика уровня знаний понижающаяся (за исключением КБР) (см. табл. 2).

Другая часто встречающаяся ситуация связана с возможной дачей гражданами свидетельских показаний. Полученные ответы о законодательно установленных нормах ответственности за отказ от дачи показаний демон-

Таблица 1

«Что является главными признаками правового государства?» (не больше трех вариантов ответа, \%)

\begin{tabular}{|l|c|c|c|c|c|c|c|}
\hline \multicolumn{1}{|c|}{ Варианты ответа } & \multicolumn{2}{|c|}{ Ростовская область } & \multicolumn{3}{|c|}{ Адыгея } & \multicolumn{2}{|c|}{ Кабардино-Балкария } \\
\cline { 2 - 8 } & $\mathbf{2 0 1 0}$ & $\mathbf{2 0 1 9}$ & $\mathbf{2 0 0 1}$ & $\mathbf{2 0 1 1}$ & $\mathbf{2 0 1 9}$ & $\mathbf{2 0 0 1}$ & $\mathbf{2 0 1 9}$ \\
\hline $\begin{array}{l}\text { верховенство закона для всех, } \\
\text { независимо от должности }\end{array}$ & $\mathbf{4 4 , 9}$ & $\mathbf{4 0 , 2}$ & $\mathbf{3 0 , 4}$ & $\mathbf{5 2 , 4}$ & 28,8 & $\mathbf{3 3 , 3}$ & $\mathbf{3 0 , 1}$ \\
\hline $\begin{array}{l}\text { все стороны жизни человека } \\
\text { регулируются законом }\end{array}$ & 18,7 & $\mathbf{4 5 , 5}$ & 21,7 & 22,9 & 28,2 & 12,5 & $\mathbf{4 5 , 3}$ \\
\hline $\begin{array}{l}\text { единство системы правовых органов - } \\
\text { суда, прокуратуры и адвокатуры }\end{array}$ & 5,3 & 14,8 & 4,4 & 6,5 & 7,4 & 2,8 & 5,6 \\
\hline $\begin{array}{l}\text { порядок, суровость и неотратимость } \\
\text { наказания за преступления }\end{array}$ & 16,0 & 10,6 & 27,7 & 18,1 & 12,3 & 19,4 & 11,2 \\
\hline $\begin{array}{l}\text { право и закон имеют болышую силу, чем } \\
\text { мораль или традиция }\end{array}$ & 11,8 & 25,4 & 4,4 & 6,7 & $\mathbf{4 2 , 9}$ & 2,8 & $\mathbf{2 8 , 6}$ \\
\hline $\begin{array}{l}\text { развитая система прав и свобод граждан } \\
\text { и их защита }\end{array}$ & $\mathbf{4 6 , 0}$ & $\mathbf{6 7 , 2}$ & $\mathbf{6 3 , 2}$ & $\mathbf{6 8 , 6}$ & $\mathbf{3 6 , 2}$ & $\mathbf{4 5 , 8}$ & $\mathbf{3 8 , 5}$ \\
\hline силь ная армия & $\mathbf{2 9 , 4}$ & 6,3 & $\mathbf{4 7 , 8}$ & 18,1 & 6,7 & $\mathbf{4 1 , 7}$ & 11,5 \\
\hline $\begin{array}{l}\text { четкая система разделение власти между } \\
\text { президентом, парламентом, судом }\end{array}$ & $\mathbf{3 0 , 5}$ & $\mathbf{2 0 , 1}$ & $\mathbf{3 9 , 1}$ & $\mathbf{5 2 , 4}$ & $\mathbf{1 7 , 2}$ & $\mathbf{2 5 , 0}$ & $\mathbf{1 6 , 1}$ \\
\hline \multicolumn{1}{|c|}{ всего } & 230,1 & 238,7 & 245,7 & 179,7 & 183,3 & 186,9 & 230,1 \\
\hline
\end{tabular}

Примечание. Многовариантные вопросы предполагают несколько вариантов ответа, поэтому сумма ответов может превышать сто процентов. 
стрирует невысокий уровень правовых знаний населений Юга России, который заметно снижается с 2001 по 2019 г. во всех рассматриваемых территориальных сегментах (табл. 3).

Этнические особенности правового сознания проявляются в ответах жителей Юга России на вопрос о том, когда можно нарушить закон. Больше всего респондентов, которые ориентируются на правовую норму как легитимный для них регулятор поведения, находятся в Ростовской области (около половины опрошенных на данном этапе и 9 лет назад). В Адыгее около трети опрошенных демонст- рирует этнически маркированные правовые нормы, и данный показатель в современный период возрос. Но треть адыгейцев также указывает, что закон нарушать нельзя ни при каких обстоятельствах, однако этот показатель с 2011 г. значительно уменьшился. В Кабардино-Балкарии за последние два десятилетия заметно сократились ориентации на этнические регуляторы и возросли гражданско-активистские. Обращает также внимание то, что в северокавказских республиках наблюдается снижение восприятия правовых норм как наказания и системы санкций (табл. 4).

Таблица 2

«На какой срок имеет право сотрудник полиции задерживать граждан без предъявления обвинения?» (один ответ, \%)

\begin{tabular}{|c|c|c|c|c|c|c|c|}
\hline \multirow[t]{2}{*}{ Варианты ответа } & \multicolumn{2}{|c|}{ Ростовская область } & \multicolumn{3}{|c|}{ Адыгея } & \multicolumn{2}{|c|}{ Кабардино-Бал кар ия } \\
\hline & 2010 & 2019 & 2001 & 2011 & 2019 & 2001 & 2019 \\
\hline на 3 ч & 30,6 & 21,2 & 18,7 & 19,4 & 15,4 & 16,9 & 21,9 \\
\hline на 1 сутки & 15,1 & 8,5 & 13,0 & 21,4 & 8,0 & 15,5 & 19,9 \\
\hline на 2 суток & 9,7 & 8,5 & 20,4 & 7,8 & 5,6 & 7,0 & 16,4 \\
\hline другое & - & 9,0 & - & 5,6 & 2,5 & - & 1,8 \\
\hline не имеет права задерживать & 34,9 & 35,4 & 43,5 & 39,8 & 34,0 & 53,5 & 26,6 \\
\hline затрудняюсь ответить, другое & 9,8 & 17,4 & 4,4 & 9 & 34,5 & 7,1 & 13,4 \\
\hline всего & 100,0 & 100,0 & 100,0 & 100,0 & 100,0 & 100,0 & 100,0 \\
\hline
\end{tabular}

Таблииа 3

«Наказывает ли закон за отказ от дачи показаний?» (один ответ, \%)

\begin{tabular}{|l|c|c|c|c|c|c|c|}
\hline \multirow{2}{*}{ Варианты ответа } & \multicolumn{3}{|c|}{ Ростовская область } & \multicolumn{3}{c|}{ Адыгея } & \multicolumn{2}{c|}{ Кабардино-Балкария } \\
\cline { 2 - 9 } & $\mathbf{2 0 1 0}$ & $\mathbf{2 0 1 9}$ & $\mathbf{2 0 0 1}$ & $\mathbf{2 0 1 1}$ & $\mathbf{2 0 1 9}$ & $\mathbf{2 0 0 1}$ & $\mathbf{2 0 1 9}$ \\
\hline не наказывает никого & $\mathbf{3 4 , 4}$ & $\mathbf{3 8 , 9}$ & $\mathbf{3 0 , 4}$ & $\mathbf{3 1 , 4}$ & $\mathbf{2 6 , 5}$ & $\mathbf{2 0 , 1}$ & $\mathbf{4 1 , 9}$ \\
\hline наказывает подозреваемого & 10,2 & 4,7 & 4,4 & 2,9 & 6,2 & 10,3 & 3,8 \\
\hline наказывает подсудимого & 6,5 & 5,3 & 0,0 & 6,8 & 7,4 & 14,1 & 6,4 \\
\hline наказывает свидетеля & $\mathbf{2 1 , 5}$ & 5,3 & $\mathbf{2 6 , 1}$ & $\mathbf{3 1 , 4}$ & 6,8 & $\mathbf{1 5 , 4}$ & 7,2 \\
\hline наказывает пострадавшего & 1,1 & 1,1 & 0,0 & 1,0 & 4,9 & 6,4 & - \\
\hline затрудняюсь ответить & $\mathbf{2 6 , 3}$ & $\mathbf{4 4 , 7}$ & $\mathbf{3 9 , 1}$ & $\mathbf{2 6 , 5}$ & $\mathbf{4 8 , 1}$ & $\mathbf{3 0 , 8}$ & $\mathbf{4 0 , 8}$ \\
\hline \multicolumn{1}{|c|}{ всего } & 100,0 & 100,0 & 100,0 & 100,0 & 100,0 & 100,0 & 100,0 \\
\hline
\end{tabular}

Таблица 4

«Когда можно нарушить закон?» (один ответ, \%)

\begin{tabular}{|l|c|c|c|c|c|c|c|}
\hline \multicolumn{1}{|c|}{ Варианты ответа } & \multicolumn{2}{|c|}{ Ростовская область } & \multicolumn{3}{|c|}{ Адыгея } & \multicolumn{2}{|c|}{ Кабардино-Балкария } \\
\cline { 2 - 8 } & $\mathbf{2 0 1 0}$ & $\mathbf{2 0 1 9}$ & $\mathbf{2 0 0 1}$ & $\mathbf{2 0 1 1}$ & $\mathbf{2 0 1 9}$ & $\mathbf{2 0 0 1}$ & $\mathbf{2 0 1 9}$ \\
\hline $\begin{array}{l}\text { когда закон не согласуется с } \\
\text { традициями народа }\end{array}$ & 10,2 & 5,1 & $\mathbf{2 1 , 9}$ & 5,4 & $\mathbf{3 1 , 3}$ & $\mathbf{2 3 , 4}$ & $\mathbf{1 3 , 8}$ \\
\hline $\begin{array}{l}\text { когда он не соответствует } \\
\text { представлениям Вашего } \\
\text { круга, семьи, друзей }\end{array}$ & 7,0 & 1,5 & 12,5 & 3,2 & 8,6 & 7,5 & 2,3 \\
\hline $\begin{array}{l}\text { когда он не соответствует } \\
\text { Вашим личным убеждениям }\end{array}$ & 11,8 & 6,2 & 18,8 & 9,7 & 0,6 & $\mathbf{1 4 , 9}$ & 8,7 \\
\hline $\begin{array}{l}\text { когда за несоблюдение закона } \\
\text { не могут наказать }\end{array}$ & 12,3 & 17,4 & 12,5 & 20,4 & 13,5 & 19,2 & 10,4 \\
\hline $\begin{array}{l}\text { закон нарушать нельзя ни при } \\
\text { каких обстоятельствах }\end{array}$ & $\mathbf{4 8 , 7}$ & $\mathbf{4 5 , 1}$ & $\mathbf{2 8 , 1}$ & $\mathbf{5 8 , 1}$ & $\mathbf{3 6 , 8}$ & $\mathbf{2 7 , 7}$ & $\mathbf{5 3 , 3}$ \\
\hline затрудняюсь ответить, другое & 10,0 & 24,7 & 6,2 & 3,2 & 9,2 & 7,3 & 11,5 \\
\hline \multicolumn{1}{|c|}{ всего } & 100,0 & 100,0 & 100,0 & 100,0 & 100,0 & 100,0 & 100,0 \\
\hline
\end{tabular}




\section{ТЕОРИЯ И ПРАКТИКА ГОСУДАРСТВЕННО-ПРАВОВОГО РАЗВИТИЯ}

На современном этапе только половина опрошенных жителей Ростовской области и Кабардино-Балкарии, а также вдвое меньше населения Адыгеи разделяют гражданско-правовые представления о доминировании права личности в обществе. Этатистские установки проявляют по $28 \%$ респондентов из ростовского и кабардино-балкарского сегментов и 46,9 \% - из адыгейского. В Адыгее также самый высокий процент указаний на приоритет прав этноса (17,3\%) (рисунок).

Десятилетием раньше в Ростовской области соотношение ответов респондентов было схожим. В Адыгее представленность гражданского типа правовых установок значительно снизилась с 2001 по 2019 г. Здесь выросли подданнические правовые ориентации. В Кабардино-Балкарии фиксируется повышающаяся динамика гражданско-правового типа установок и уменьшающаяся - этатистских и этноцентрических представлений (рисунок).

\section{Выводы}

Адекватный уровень знания и понимания правовых регуляторов современной жизни выступает одним из важнейших условий стабильного развития и социетальной целостности поликультурного макрорегиона. Вместе с тем эмпирические результаты проведенных исследований показывают низкий уровень конкретных правовых знаний населения во всех рассматриваемых территориальных субъектах
Юга России: меньшинство опрошенных жителей продемонстрировало осведомленность по вопросам о базовых признаках правового государства, существующих законодательных нормах в случае административного задержания и дачи свидетельских показаний. Причем от первого к последнему этапам исследования динамика уровня знаний понижающаяся.

Приоритет права далеко не всегда проявляется в установках опрошенного населения Юга России. Для значительного числа опрошенных ограничение прав человека допустимо, как правило, в целях обеспечения социально-политической безопасности и устойчивости. На этом фоне в Ростовской области на разных этапах исследования проявляется устойчивая группа респондентов (около половины опрошенных), для которых правовая норма является легитимным регулятором поведения. В республиканском сегменте ситуация подвижная, обнаруживается запаздывающая динамика правовых установок гражданского типа в Республике Адыгея и ускоряющаяся - в Кабардино-Балкарии.

\section{ПРИМЕЧАНИЕ}

${ }^{1}$ Исследование выполнено при финансовой поддержке РФФИ в рамках научного проекта № 19-011-00270.

The reported study was funded by RFBR in the framework of scientific project number 19-011-00270.

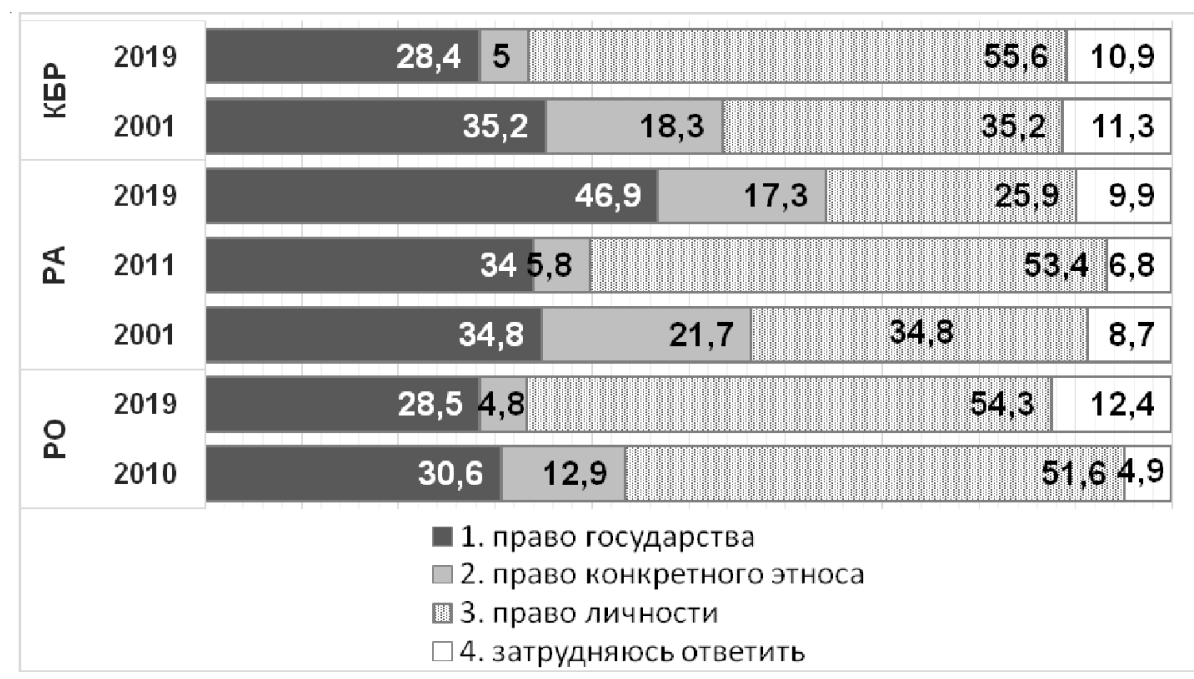

«Права какого субъекта общества должны доминировать в России для обеспечения нормальной жизни людей?» (один ответ, \%) 


\section{ТЕОРИЯ И ПРАКТИКА ГОСУДАРСТВЕННО-ПРАВОВОГО РАЗВИТИЯ}

На современном этапе только половина опрошенных жителей Ростовской области и Кабардино-Балкарии, а также вдвое меньше населения Адыгеи разделяют гражданско-правовые представления о доминировании права личности в обществе. Этатистские установки проявляют по $28 \%$ респондентов из ростовского и кабардино-балкарского сегментов и 46,9 \% - из адыгейского. В Адыгее также самый высокий процент указаний на приоритет прав этноса (17,3\%) (рисунок).

Десятилетием раньше в Ростовской области соотношение ответов респондентов было схожим. В Адыгее представленность гражданского типа правовых установок значительно снизилась с 2001 по 2019 г. Здесь выросли подданнические правовые ориентации. В Кабардино-Балкарии фиксируется повышающаяся динамика гражданско-правового типа установок и уменьшающаяся - этатистских и этноцентрических представлений (рисунок).

\section{Выводы}

Адекватный уровень знания и понимания правовых регуляторов современной жизни выступает одним из важнейших условий стабильного развития и социетальной целостности поликультурного макрорегиона. Вместе с тем эмпирические результаты проведенных исследований показывают низкий уровень конкретных правовых знаний населения во всех рассматриваемых территориальных субъектах
Юга России: меньшинство опрошенных жителей продемонстрировало осведомленность по вопросам о базовых признаках правового государства, существующих законодательных нормах в случае административного задержания и дачи свидетельских показаний. Причем от первого к последнему этапам исследования динамика уровня знаний понижающаяся.

Приоритет права далеко не всегда проявляется в установках опрошенного населения Юга России. Для значительного числа опрошенных ограничение прав человека допустимо, как правило, в целях обеспечения социально-политической безопасности и устойчивости. На этом фоне в Ростовской области на разных этапах исследования проявляется устойчивая группа респондентов (около половины опрошенных), для которых правовая норма является легитимным регулятором поведения. В республиканском сегменте ситуация подвижная, обнаруживается запаздывающая динамика правовых установок гражданского типа в Республике Адыгея и ускоряющаяся - в Кабардино-Балкарии.

\section{ПРИМЕЧАНИЕ}

${ }^{1}$ Исследование выполнено при финансовой поддержке РФФИ в рамках научного проекта № 19-011-00270.

The reported study was funded by RFBR in the framework of scientific project no. 19-011-00270.

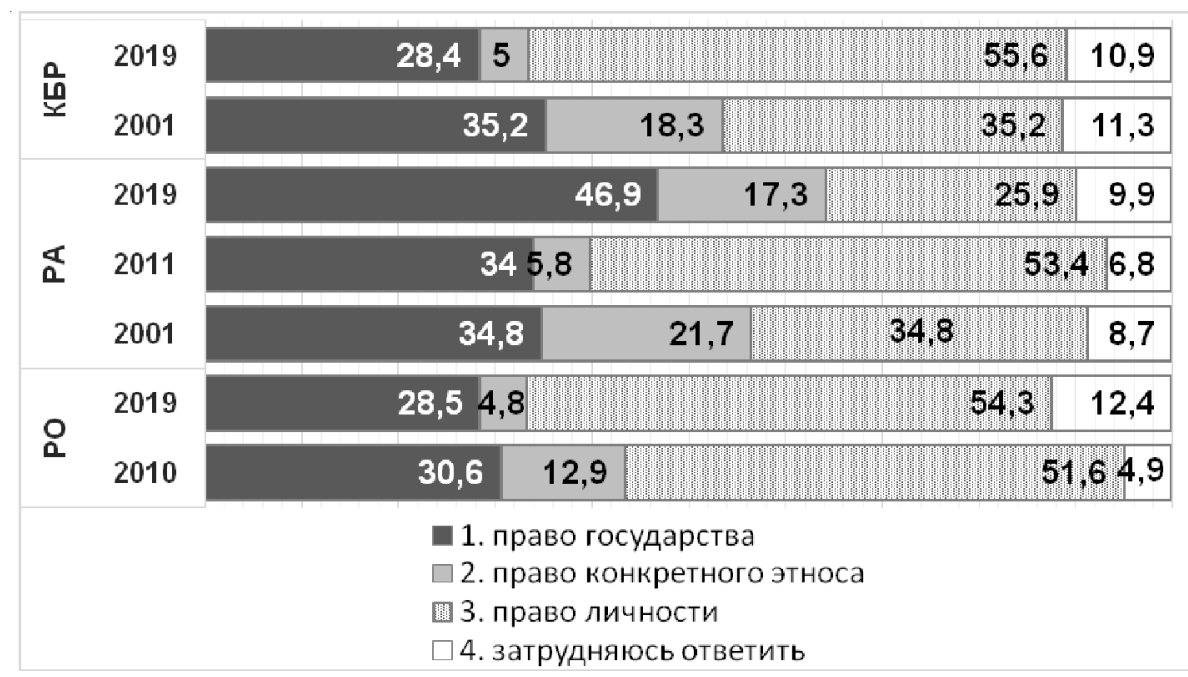

«Права какого субъекта общества должны доминировать в России для обеспечения нормальной жизни людей?» (один ответ, \%) 


\section{ТЕОРИЯ И ПРАКТИКА ГОСУДАРСТВЕННО-ПРАВОВОГО РАЗВИТИЯ}

11. Silbey S. After Legal Consciousness. Annual Review of Law and Social Science, 2005, no. 1, pp. 323-368. DOI: https://doi.org/10.1146/ annurev.lawsocsci.1.041604.115938.

12. Rogers, A. The Value of Ethnography and Legal Consciousness in a Legally Plural Context.
Abstract from Socio-Legal Studies Association Conference (Bristol, United Kingdom, 2729 March 2018), 2018, pp. 41-42. URL: https:// docs.wixstatic.com/ugd/af48eb_1b24410b4e 934b96b50b0b7eb934f86f.pdf (accessed 10 July 2019).

\section{Information about the Authors}

Lyudmila V. Klimenko, Doctor of Sciences (Sociology), Professor, Department of Business in Hospitality, Southern Federal University, Bolshaya Sadovaya St., 105/42, 344006 Rostov-on-Don, Russian Federation, lucl@yandex.ru, https://orcid.org/0000-0001-7696-7830

Oksana Yu. Posukhova, Candidate of Sciences (Sociology), Associate Professor, Department of Regionalism and Eurasian Studies, Southern Federal University, Bolshaya Sadovaya St., 105/42, 344006 Rostov-on-Don, Russian Federation, belloks@yandex.ru, https://orcid.org/0000-0002-5334-9527

Pavel E. Budaev, Candidate of Sciences (Sociology), Associate Professor, Department of Management Technology and Tourism Industry, Southern Federal University, Bolshaya Sadovaya St., 105/42, 344006 Rostov-on-Don, Russian Federation, pavelbudaev@list.ru, https://orcid.org/0000-0002-2950-5542

\section{Информация об авторах}

Людмила Владиславовна Клименко, доктор социологических наук, профессор кафедры бизнеса в сфере гостеприимства, Южный федеральный университет, ул. Большая Садовая, 105/42, 344006 г. Ростов-на-Дону, Российская Федерация, lucl@yandex.ru, https://orcid.org/0000-0001-7696-7830

Оксана Юрьевна Посухова, кандидат социологических наук, доцент кафедры регионалистики и евразийских исследований, Южный федеральный университет, ул. Большая Садовая, 105/42, 344006 г. Ростов-на-Дону, Российская Федерация, belloks@yandex.ru, https://orcid.org/0000-0002-5334-9527

Павел Евгеньевич Будаев, кандидат социологических наук, доцент кафедры технологии управления и индустрии туризма, Южный федеральный университет, ул. Большая Садовая, 105/42, 344006 г. Ростов-на-Дону, Российская Федерация, pavelbudaev@list.ru, https://orcid.org/0000-0002-2950-5542 